\title{
DOCUMENTO
}

\section{Centrais sindicais: ferramentas das lutas políticas dos trabalhadores}

Nem sempre, nos paises onde existe apenas uma central sindical, o movimento operário tem sua ação unificada politicamente $e$, por outro lado, a pluralidade de centrais também não significa, necessariamente, a fragmentação do poder político da classe operária. A unidade fator fundamental da força operária - só existe na ação e, às vezes, só é alcançada pela explicitação das diferentes propostas de organização dos trabalhadores.

Tudo depende da tradição do movimento operário, que está intimamente associada à historia e à evolução politica de cada país. Por isso a organização do movimento dos trabalhadores varia de um pais para outro e se propoe tarefas diferentes, de acordo com as transformaçסes que cada nação vive. Nestas lutas, as centrais sindicais, na medida que aglutinam os trabalhadores em nivel nacional, são referências muito importantes.
LUA NOVA quis trazer mais subsidios e informaçoes sobre esse tema crucial para os trabalhadores brasileiros, que, recentemente, criaram a CUT - Central Única dos Trabalhadores - e a CONCLAT - Coordenação Nacional da Classe Trabalhadora.

Discutem o tema Roberto Digón, secretário geral do Sindicato dos Trabalhadores do Tabaco da República Argentina e membro do Conselho Diretor da Confederação Geral dos Trabalhadores - CGT; Manoel Cordovan, membro da Coordenadoria Nacional Sindical do Chile - CNS; Carlos Minalo, ex-assessor das Comissoes Operárias para assuntos sindicais internacionais, da Espanha, $e$ Gian Andrea Sandri, responsável de Relaçoes Internacianais da Confederação Geral Italiana dos Trabalhadores - CGIL, em particular para assuntos latino-americanos, todos entrvistados por Edison Nunes. 
PERGUNTA - Qual é o papel desempenhado pelas centrais sindicais dos seus paises?

CORDOVAN - No Chile, é tão importante que, se ela não existisse, de todas as maneiras a estaríamos construindo. Estamos lutando pelo fim da ditadura. $O$ que ocorre com todos os latino-americanos. Para nós, a Coordenadoria Nacional Sindical é uma ferramenta de unidade dessa luta. Neste ponto, se abre uma pequena cortina na esperança por democracia no Chile. Começamos por um ciclo de protesto até chegar a uma grande greve nacional pelo fim da ditadura.

Iniciamos esta luta, de forma franca e aberta, em 1980, com uma convenção de mais de 600 dirigentes sindicais, para a qual sempre agradeço o papel que tem desempenhado a Igreja Católica no Chile que, como dizemos, nos emprestou o "guarda-chuva" para a reunião. Além da Igreja, mais do que nunca, a solidariedade internacional ajuda a manter esta grave e terrível luta contra a ditadura.

Mas isso traz muitas coisas dificeis de resolver. $O$ desemprego supera $30 \%$ em meu país. Somado ao subemprego, esse número passa de $50 \%$. Isto gera entre os trabalhadores, um imenso temor de ser despedido. Por isso fazemos os protestos fora do local de trabalho.

\section{DIGÓN - O projeto político da} Confederação Geral dos Trabalhadores da República Argentina CGT exige que o sindicalismo participe da política, porque é na política que são tomadas as decisões. Como criamos a maior fonte de rique- zas do país, temos os mesmos direitos que outros setores da sociedade para participar das grandes decisões.

MINALO - O fato de haver duas grandes centrais sindicais na Espanha - a União Geral dos Trabalhadores, UGT, com proposta socialista, e as Comissoes Operárias, que reúne diversas tendências, com uma presença importante de militantes do Partido Comunista representa a mudança de um sindicato corporativista para um sindicato com garantias democráticas. Para saber o que significa uma central, deve-se perguntar qual o poder que se quer para a classe operária.

Esse poder não pode se limitar a votar em eleiçðes sindicais ou reivindicar. Deve compreender um maior controle do processo de trabalho e das relaçðes entre o capital e o trabalho, que se materializam concretamente dentro da empresa. Por isso a organização da ação sindical parte do próprio local de trabalho, através de comitês de empresa, que congregam os trabalhadores de uma fábrica, estejam ou não filiados a uma central. Neles os operários têm oportunidades de exercer um certo poder dentro da empresa.

A organização parte do local de trabalho mas não se esgota aí, porque isso nos remeteria a uma visão corporativista do sindicalismo, onde cada categoria pode conseguir benefícios para si, sem haver uma dimensão de classe. Uma das funçð̃es das centrais é dar uma perspectiva de classe às lutas dos trabalhadores.

Além do comitê, existe nas empresas a seção sindical, que é a parte 
de filiados de uma central dentro de cada empresa. Pode coincidir que os representantes do comitê de empresa sejam os mesmos da seção sindical de uma das centrais. A atuação da seção sindical visa dinamizar as propostas da central sobre as negociações da formação sindical, e o esclarecimento e informação, dentro das empresas.

\section{As centrais $e$}

\section{as negociações}

EDISON - Qual é o papel das centrais na formulação dos acordos ou contratos de trabalho?

MINALO - As negociaçðes podem se dar através dos comitês de empresa em assuntos específicos. Mas dåo-se principalmente através das seçðes sindicais de cada central e suas federações em nível estadual ou nacional, nas reivindicaçōes da categoria. Os comitês e sessőes também zelam pelo cumprimento efetivo de acordos celebrados em outros niveis.

CORDOVAN - A Coordenadoria Nacional Sindical do Chile, conforme a legislação da ditadura, não tem nenhum valor. Segundo o governo, é somente uma entidade "romântica", sem finalidades práticas. A ditadura deixou a central fora dos assuntos reivindicativos, bem como as confederaçōes e federaçð̋es. Quem negocia são os sindicatos de base com suas respectivas indústrias. Estes são organizados por empresa, sendo que seus dirigentes são escolhidos por eleiçð̃es diretas. Mas é uma legislação tão má, tão "leonina", que a negociação é, na verdade, uma trapaça. Favorece $100 \%$ a classe patronal. $\mathrm{E}$, além do mais, quem julga as questões do trabalho é um tribunal arbitrário.

DIGÓN - Na Argentina, não é a Confederação Geral dos Trabalhadores que negocia diretamente com os patrões. Nas fábricas existem comissð̃es internas, que são eleitas pelos trabalhadores, com o poder de discutir os problemas internos de fábrica: melhora das condições de trabalho, segurança, etc. Mas, se enfrentam algum dilema que não têm condição de resolver, podem pedir a intervenção direta do sindicato. Os trabalhadores elegem em cada estado sua seção sindical, que depende do sindicato nacional. Este é um sindicato único por categoria profissional, e também é eleito pelo voto direto e secreto de todos os filiados. De 95 a $98 \%$ dos trabalhadores participam dessas eleições.

Os convênios coletivos de cada categoria de trabalho são discutidos em nível nacional por uma comissão paritária, metade formada por companheiros dos sindicatos e a outra metade escolhida através do voto direto de cada uma das fábricas. Quando a negociação chega a um ponto limite - para se decidir sobre a aceitação do convênio coletivo ou para decretar a greve ou outras medidas de ação - , quem decide sempre é a Assembléia Geral do sindicato, que é o seu organismo máximo e que está acima do Conselho Diretivo Nacional do sindicato. $E$ também através da Assembléia 
Geral que os trabalhadores resolvem a filiação de seu sindicato à CGT.

EDISON - Mas se são as comissões paritárias de cada sindicato, por categoria profissional, que ne- gociam, por que uma central sindical?

DIGONN - Porque a central sindical não é o sindicato único. Podem-se conseguir os melhores acordos coletivos de trabalho, mas se não há um controle da produção,

\section{POR QUE OS ITALIANOS NÃO CRIAM UMA CENTRAL ÚNICA.}

PERGUNTA - Muito se tem falado da unificaçao das três principais tendências do sindicalismo italiano, já se conseguiu a criação de uma federação unitária. Por que, então, a persistência das centrais sindicais?

SANDRI - Desde 1974 se fala da criação da central única na Itália. Isto é, que a federação unitária poderia ser o começo de uma central única. Mas isso não aconteceu. $\mathrm{O}$ que houve até agora foi um processo de centralização das decisoes, que está sendo comum na Europa. Isto é, a federação unitária começa a assumir um papel quase de direção do movimento. Um papel que não lhe pertence, pelo menos nos estatutos. E esta centralização é feita em detrimento do poder das federações de categoria e dos quadros intermediários.

A formação de uma central única nđo se deu, em primeiro lugar, porque os partidos políticos pressionam muito alguns setores sindicais para não se chegar a ela. Pela simples razão de que, nesta, os comunistas teriam a maioria.

A outra consideração pertence à história do movimento sindical italiano. As três centrais, por razões culturais e projeto diferentes, decidiram tomar o caminho de um processo federativo e não completamente unjtário, onde estão presentes os três participantes do movimento operário italiano: comunistas, socialistas e catolicos. Mas o debate ainda não se encerrou.

\author{
A importância do \\ avanço político
}

EDISON - Do seu ponto de vista, a luta polltica do sindicato deve conduzir à central única?

SANDRI - No momento năo existem condiçðes objetivas ou subjetivas para isso. $O$ que se iniciou foi um processo de mediaçao entre os três componentes políticos do sindicalismo italiano, que deu resultados positivos para o movimento sindical.

Outro problema que dificulta a criação da central única é que se o movimento sindical avança, e o quadro político năo muda, as conquistas sindicais são muito difíceis de defender. Isso foi característica da Itália nestes anos. O sindicato italiano alcançou, através de práticas políticas e sindicais democráticas, formas elevadas de participação com vistas à vida política. Isso não correspondeu a uma transformação politica na sociedade italiana. Isto é, o sindicato italiano se encontrou com governos mais ou menos estáveis, que são sempre os mesmos e que não puderam ir ao encontro das exigências do sindicato. 
se não há um controle dos preços dos artigos de primeira necessidade, os salários sobem pelas escadas enquanto os preços vão pelo elevador. Então, o que temos de obter é o controle das medidas econômicas e da produção, e aí poderemos

\section{Tarefas $e$}

\section{limites do sindicato}

Nos anos 70, pensou-se que o papel dos sindicatos seria o de dirigir a transformação da sociedade italiana. E isso não é certo! Se a força dos sindicatos e suas propostas não são acompanhadas de transformaçoes políticas na sociedade, transformaçðes também do governo, as conquistas se tornam muito dificeis de defender. Por isso é que os sindicalistas da CGIL acham importante uma transformação política na Itália, que conduza a uma alternativa de governo. A COIL aprovou uma resolução na qual pedia a alternativa democrática para a sociedade italiana.

EDISON - Isso nos remete d̀ relação dos sindicatos com os partidos. Existem atritos entre as lideranças partidárias e sindicais?

SANDRI - O problema é que o sindicato italiano, para se manter unido e autônomo, necessita de uma mediação entre as diferentes posiçס̃es políticas que o compóem. Assim, quando se chega a uma posição unitária, esta não pode satisfazer nem ao Partido Comunista nem ao Socialista ou ao Democrata Cristão. Satisfaz as necessidades dos trabalhadores italianos. Mas cremos que o sindicato tem suas tarefas, mas também seus limites. Cabe aos partidos políticos e ao parlamento a tarefa de dirigir a mudança da sociedade italiana. alcançar uma vida mais digna no país. Esta luta cabe à CGT.

EDISON - Agora, gostaria que vocês falassem sobre a relação entre os partidos políticos e as centrais. Como é isso?

MINALO - Na Espanha, existe uma tensão entre sindicato e partido, e não há como ou por que camuflá-la. Nesse sentido, grande parte dos militantes sindicais tem mostrado, na prática, um comportamento bastante independente dos partidos. De forma que, em questões práticas, têm surgido publicamente discordâncias entre as centrais sindicais e os partidos.

CORDOVAN - Nós fizemos uma pequena "abertura" política no Chile. Depois vieram os partidos. Por isso as organizaçðes sindicais têm de estar presentes à mesa, junto com os partidos, para elaborar as alternativas para o Chile. Não seremos mais os parentes pobres, olhados por cima dos ombros, como meros agentes de conflito, ou bandidos, como a ditadura nos taxou. Somos dirigentes sindicais e exigimos que o projeto contemple o término das leis repressivas e das que regem o atual código de trabalho.

EDISON - Existem diferenças politicas entre os trabalhadores. Como essas diferenças se expressam na central sindical?

DIGÓN - Mais ou menos $85 \%$ dos companheiros das diretorias dos sindicatos argentinos, das seçð̋es e das comissőes de fábrica, têm uma ideologia peronista. Acontece 
que o grande projeto realizado pelo peronismo - a dignificação da classe trabalhadora e a participação política das massas - atraiu a maioria da classe trabalhadora para o seu partido. Mas isso não é um obstáculo para que companheiros com outra ideologia, ou de outros partidos, participem ativamente dos órgãos diretivos. Comunistas, socialistas radicais e cristãos também fazem parte dos órgãos de direção sindical. Realmente, há aí um grande pluralismo.

\section{Tarefas e}

\section{limites do sindicato}

CORDOVAN - Apesar da ilegalidade, o pluralismo está se dando no Chile. A Coordenadoria Nacional Sindical abriga todas as tendências do movimento sindical na luta contra a ditadura. Outros estão defendendo um sindicalismo ideológico e pensam que deverão nascer três centrais diferentes: uma marxista, outra social-democrata e uma terceira da democracia cristã. De qualquer forma, este assunto não estará na pauta antes de se liquidar com a ditadura.

MINALO - Durante a ditadura de Franco, existia na Espanha uma unidade, porque não afloravam ainda as divergências de concepçð̃es e projetos políticos. Conseqüentemente, várias posições políticas estavam presentes, o que nunca impediu uma ação conjunta. A luta se deu com todas as forças progressistas atuantes na sociedade: anarquistas, católicos, socialistas, comunistas, carlistas - que são monarquistas - e até mesmo certos setores falangistas.

$O$ problema surge na medida que se vão materializando diversas correntes sindicais. Aí tem-se de aceitar o pluralismo na luta e se pensa a unidade como algo que se dá na ação e não na criação de uma única central sindical. O pluralismo sindical apenas cristaliza as diferentes alternativas políticas forjadas na história do movimento operário espanhol.

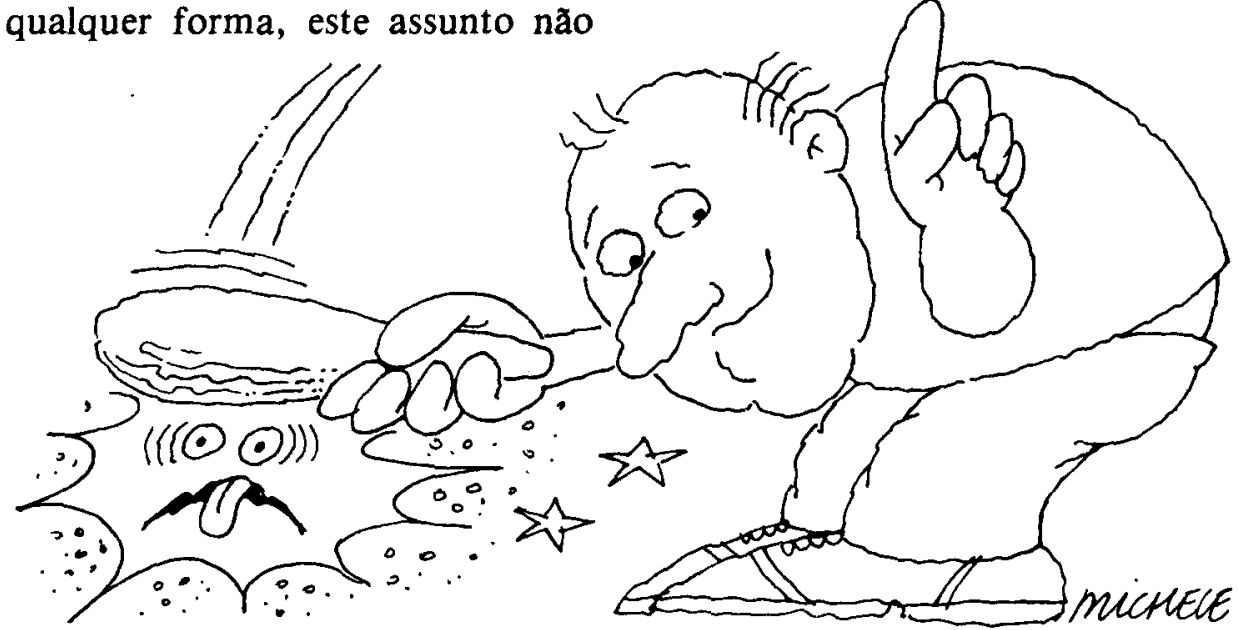

